\title{
Preparation and characterization of bijoypur clay- crystalline cellulose composite for application as an adsorbent
}

\author{
Md. Minhajul Islam ${ }^{1}$, M. Nuruzzaman Khan ${ }^{1}$, Shanta Biswas ${ }^{1}$, Tasrina Rabia Choudhury ${ }^{2}$, Papia Haque ${ }^{1}$, Taslim U Rashid ${ }^{1}$ and Mohammed \\ Mizanur Rahman ${ }^{1 *}$ \\ ${ }^{1}$ Department of Applied Chemistry and Chemical Engineering, Faculty of Engineering and Technology, University of Dhaka, Dhaka, Bangladesh \\ ${ }^{2}$ Analytical Chemistry Laboratory, Chemistry Division, Bangladesh Atomic Energy Centre, Dhaka, Bangladesh
}

\begin{abstract}
Biocomposite prepared from cellulose and Bijoypur clay (Kaolinite) exhibited enhanced properties compared to their original counterparts. Cellulose extracted from jute fiber and Bijoypur clay modified with a surfactant were combined to fabricate a biocomposite by exfoliation-adsorption method. A comparative study was carried out to determine thermal stability and adsorption capacity of the composite and raw materials. Characterizations of the biocomposites were carried out by Fourier transform infrared spectroscopy (FT-IR), Differential Scanning Calorimetry (DSC), Thermogravimetric Analysis (TGA) and Scanning Electron Microscopy (SEM) analysis. FT-IR analysis showed successful modification of clay and incorporation of polymer and organoclay in the biocomposites. The composite has exhibited better thermal properties with increasing clay percentage in TGA analysis. Moreover, the composite showed improved adsorption capacity of hexavalent chromium in stock solution compared to natural adsorbent such as cellulose and clay.
\end{abstract}

\section{Introduction}

Polymer-clay biocomposites have attracted special attention in recent times because of their advantages over conventional polymer composites. Such type of composites prepared in recent studies contain synthetic polymers such as epoxy [1-3], methyl methacrylate [4], nylon [5], polyaniline [6], polyethylene [7] and polypropylene [8]. However, the feedstock for most the synthetic polymers are fossil fuel which is a major cause of environmental pollution due to requirement of excessive energy and emission of fumes during production. Moreover, nonbiodegradability of synthetic polymers leads to disposal and recycling problem making these composites less endearing. On the other hand, natural biodegradable polymers can be easily incorporated to fabricate biocomposites which exhibit enhanced properties as well as overcome the problems faced by synthetic polymer based counterparts [8,9].

Biodegradable polymers which have been used for making composites are cellulose $[10,11]$, chitosan $[8,12]$, polylactide (PLA) [13], gelatin [14] and poly (3-hydroxy butyrate) (PHB) [15] etc. Among them, cellulose is a ubiquitous and renewable polymer present in nature as a structural material of plants. The yearly biomass production of cellulose is about one trillion tones which implies the inexhaustible nature of cellulose as natural polymer raw material [16]. Cellulose nanocrystals (CNCs) have been used indifferent types of applications such as in textiles, gels, optics, aircraft, pharmaceuticals, food additives, composites, electronic products, tooth repair, bone replacement and adsorption [17]. Cellulose is a polysaccharide containing about 1500 $\beta$-glucose units where the chains are connected together with hydrogen bonds [18]. Importantly, cellulose contains hydroxyl $(-\mathrm{OH})$ groups on the glucose ring acting as coordination sites to heavy metal ions making it an attractive natural adsorbent [19-21].

Clay is a readily available and cheap raw material [22]. Clay is hydrous aluminosilicates making up the colloid fraction of soils, rock and sediments [23]. Clays contain exchangeable cations and anions on the surface, which can be used to remove pollutants through ion exchange or adsorption or both. Large surface area, layered structure, mechanical stability and eco-friendliness have made clay an attractive proposition as composite material [24]. Clays are categorized into several types such as montmorillonite, kaolinite, pyrophyllite, chlorite, hectorite, halloysite and bentonite according to their morphology and chemical composition $[25,26]$. In this study, Bijoypur clay, a type of locally available kaolinite clay, is used for the fabrication of biocomposite. The major phases present in Bijoypur clay are kaolinite, halloysite and quartz. Bijoypur clay has high content of $\mathrm{SiO}_{2}(70.08$ $\%)$, it also has significant amount of $\mathrm{Al}_{2} \mathrm{O}_{3}(27.24 \%)$ and relatively low amount of $\mathrm{Fe}_{2} \mathrm{O}_{3}$ (1.03\%) and $\mathrm{TiO}_{2}(1.65 \%)$ [27].

Chromium, a major heavy metal pollutant, is present in the nature as trivalent or hexavalent state. While trivalent chromium occurs naturally and is an important micronutrient, (requirement is 50-200 $\mu \mathrm{g}$ per day) which helps the body to metabolize protein, fat and sugar, hexavalent chromium is usually of anthropogenic origin and causes serious health hazards such as skin and mucous membrane irritation, eczema and is also reportedly carcinogenic in nature $[28,29]$. The main sources of hexavalent chromium contamination are electroplating industries, leather tanning industries, pigment manufacturing industries and metal finishing industries where chromium is as

Correspondence to: Mohammed Mizanur Rahman, Department of Applied Chemistry and Chemical Engineering, Faculty of Engineering and Technology, University of Dhaka, Dhaka, Bangladesh, Tel: +880-2-9661920-70/7392; Fax: +880-2-9667222; E-mail: mizanur.rahman@du.ac.bd

Key words: Biopolymer, cellulose, bijoypur clay, composite

Received: June 03, 2017; Accepted: July 17, 2017; Published: July 20, 2017 
decorative and functional purposes. Due to the health hazards $\mathrm{Cr}$ (VI) possesses, the remediation of $\mathrm{Cr}(\mathrm{VI})$ contaminated industrial effluents is attracting interest. The main strategies that have been used for $\mathrm{Cr}$ (VI) removal from effluents are ion exchange [30], precipitation [31], membrane filtration [32] and sorption [33]. Composite prepared from organic (cellulose) and inorganic (clay) materials is expected to exhibit good heavy metal adsorption capacity in aqueous solution due to their structure. Moreover, it is developed from biomaterials so an efficient, green, economic and low-cost adsorbent with good adsorption capacity is expected.

In this study, a biocomposite is prepared from materials available in the nature with the intention of removing a hazardous heavy metal such as chromium. The composite was prepared by exfoliationadsorption method where organoclay was exfoliated in a solvent in which the polymer cellulose is soluble.

\section{Materials and methods}

\section{Materials}

Jute fiber was supplied by Bangladesh Jute Research Centre. While Bijoypur clay was collected from Bijoypur area, Netrekona district by Bangladesh Insulator \& Sanitary ware Factory (BISF) who supplied us the clay for this study. Dodecylamine was obtained from SigmaAldrich, 3050 Spruce Street, St. Louis, Sweden, hydrochloric acid from Merck KGaA, 64271 Damstadt, Germany and sodium hydroxide from Loba Chemie Pvt. Ltd., 107, Mumbai 400005, India. Deionized water was used throughout the experiment. Every chemical used for this study was analytical grade.

\section{Instrumentation}

The characterization of the composite and its components were carried out in Centre for Advanced Research in Science (CARS), University of Dhaka, Bangladesh and Atomic Energy Center, Shahbagh, Dhaka.

Thermo gravimetric analysis (TGA) was carried out using TG00260 machine with Serial NO. C300346, SHIMADZU Corp, Japan. The samples were taken in an aluminum cell. Nitrogen was supplied to maintain the inert atmosphere. Initial temperature was room temperature, while the final temperature of analysis was $600^{\circ} \mathrm{C}$. The rate of increase of temperature was $10^{\circ} \mathrm{C}$ per minute. The hold time was 5 minutes.

FTIR analysis was performed by using ATR-FTIR (Attenuated Total Reflectance/ Fourier Transforms Infrared) spectrophotometer (Model-FT-IR8400S spectrophotometer, SHIMADZU Corp, Japan). The spectra were recorded in the transmission band mode in the range of 4000-400 cm-1. $200 \mathrm{mg}$ of spectroscopic grade dry $\mathrm{KBr}$ and $1 \mathrm{mg}$ powdered sample was mixed by grinding in an agate mortar. $100 \mathrm{mg}$ of this mixture was used to make pellets. The resolution was $4 \mathrm{~cm}^{-1}$. The number of scans were 30 times.

DSC was carried out using a DSC-60 (SHIMADZU Corp, Japan), maintaining ASTM standards 2008a, flow rate $20 \mathrm{ml} / \mathrm{min}$, temperature rate $10 / \mathrm{min}$ and in aluminum pan. Change of heat per gram of sample was recorded at a constant temperature for 60 minutes with a computerized system in dry nitrogen environment.

SEM pictures were taken at $20 \mathrm{kV}$ with a JSM-6490LA, Jeol, Japan and magnifications were $500 \times, 1000 \times$ and $2000 \times$.

Atomic absorption spectroscopy (AAS) was used for the determination of heavy metal concentration in standard samples of chromium. The atomizer in which the analyte was atomized was flame type. In flame atomization, fixed aliquot of measurement solution was converted into an aerosol in nebulizer and transported into the flame. Then the aliquot was vaporized and atomized. The filtrate solutions obtained in adsorption were analyzed by AAS. For the detection of heavy metal, Varian AA 240 FS atomic absorption spectrophotometer was used. The wavelength was $357.9 \mathrm{~nm}$ and slit width was $0.2 \mathrm{~nm}$ and lamp current was $7 \mathrm{~mA}$.

\section{Purification and modification of clay}

Acid purified clay usually contains hydrated $\mathrm{Na}^{+}$and $\mathrm{K}^{+}$ions. But layered silicates are miscible only with hydrophilic polymer. To make clay miscible with other polymer matrices, one must convert the normally hydrophilic silicate surface to an organophilic one. Modification was carried out using a method described by Yano et el. (2008) and adapted in the laboratory [34]. Long chain carbon molecules were incorporated into the layered silicate structure of clay by reacting with dodecylamine.

First $10 \mathrm{~g}$ of clay was dispersed in $200 \mathrm{~mL}$ of water. It was stirred in a magnetic stirrer to make homogenous slurry. The slurry was heated to $80^{\circ} \mathrm{C}$. Then $4.5 \mathrm{~g}$ of dodecylamine was taken into a separate beaker and $100 \mathrm{~mL}$ of water was added to this. Finally, $4.8 \mathrm{~mL}$ of concentrated $\mathrm{HCl}$ was added to this solution and heated to $80^{\circ} \mathrm{C}$. The previously prepared dispersed clay was added to dodecylamine solution. It was stirred vigorously for 1 hour. The white precipitate was isolated and washed by centrifuge and stirred for 1 hour. The process was repeated two times to remove the residue of ammonium salt of dodecylamine. The product was then filtered and organically modified clay was obtained after oven drying at $80^{\circ} \mathrm{C}$. It was then stored in desiccator for further experiments and composite preparation.

\section{Preparation of crystalline cellulose from jute fiber}

Dried jute fiber was soaked in absolute ethanol $(5 \mathrm{~mL} / \mathrm{g}$ jute $)$ and then washed with distilled water. The washed sample was again dried at $100^{\circ} \mathrm{C}$ in an oven for 2 hours. Wax and fat free dried jute fiber was treated with $10 \%(\mathrm{w} / \mathrm{v}) \mathrm{NaOH}$ solution at $60^{\circ} \mathrm{C}$ to remove lignin. The black liquor containing lignin was removed by frequent washing with distilled water until all the alkali was removed. Delignified jute fiber was bleached with $5 \% \mathrm{NaOCl}(5 \mathrm{~mL} \mathrm{NaOCl} / \mathrm{g}$ delignified jute fiber) by constant stirring. This was then frequently washed with distilled water and dried in an oven at $100{ }^{\circ} \mathrm{C}$ for 2 hours. The bleached jute fiber was hydrolyzed by $64 \%$ sulphuric acid solution at $55-60^{\circ} \mathrm{C}$ for 5 hours ( $9 \mathrm{~mL}$ acid solution/g bleached jute fiber). After hydrolysis, this was frequently washed with distilled water by centrifugation at 10000 rpm for 45 minutes to remove free acid. Centrifugation was repeated 5 times. Finally white cellulose crystal was collected from the vial of centrifuge and dried in a freeze drier.

\section{Preparation of composite}

Clay-crystalline cellulose composites were prepared by dissolution of cellulose in an alkali solution with an additive. Modified clay was dispersed and added to this solution to obtain composites as powder.

$20 \mathrm{~g} \mathrm{LiOH-Urea-Water}$ solution was prepared, then desired amount of modified clay was added to this solution. The amount of clay used was varied from $1 \mathrm{~g}$ to $4 \mathrm{~g}$ to make different composition of composite. The clay dispersion was agitated using a sonicator for 2 minutes. Then it was subjected to mechanical stirring at $1200 \mathrm{rpm}$ for 2 hours using a magnetic stirrer machine. 
The stirred dispersion was kept in a freezer to cool it to $-12^{\circ} \mathrm{C}$. The dispersion was then taken out after 4 hours and immediately desired amount of crystalline cellulose was added. This was stirred for 10 minutes at $1200 \mathrm{rpm}$ until crystalline cellulose dissolved in the solution. A blend solution of clay and cellulose was obtained. After stirring, the blend solution was then thawed and finally it was ready for regeneration. Acetone was added to the solution to allow regeneration of cellulose. After 30 minutes, the solution was spread on a petri dish and left to allow further regeneration. The obtained material was then centrifuged to separate the composite material from liquid phase. This was washed several times and dried in an oven at $60^{\circ} \mathrm{C}$. Different compositions of composites prepared by varying weight percentage are shown below (Table 1).

\section{Adsorption studies}

Adsorption capacity of composite was determined by contacting with $25 \mathrm{ppm} 20 \mathrm{ml}$ chromium stock solution. To prepare a chromium stock solution of $1000 \mathrm{ppm}$ or $1000 \mathrm{mg} / \mathrm{l}, 0.2892 \mathrm{~g} \pm 0.0002 \mathrm{~g}$ potassium dichromate $\left(\mathrm{K}_{2} \mathrm{Cr}_{2} \mathrm{O}_{7}\right)$ was taken in a $100 \mathrm{ml}$ volumetric flask with $4 \mathrm{ml}$ deionized water. $0.5 \mathrm{ml}$ sulfuric acid (98\%) was added and cooled to room temperature. Finally, it was filled up to the mark with deionized water.

Composites CC1, CC2, CC3, CC4, CC5, CC6 and CC7 were used for the adsorption study. Starting materials raw clay, modified clay and crystalline cellulose were also used for adsorption of chromium to make a comparative study of adsorption capacity after 2 hours of shaking in a reciprocal shaker. To get a fair comparison, the conditions were strictly maintained. The conditions of various parameter of adsorption test are shown below. (Table 2)

The equation used to calculate the capacity was-

$q_{a}=\frac{V\left(C_{i}-C_{e}\right)}{m}$

Where,

$\mathrm{q}_{\mathrm{a}}=$ absorption capacity (mg. $\left.\mathrm{g}^{-1}\right)$;

$\mathrm{C}_{\mathrm{i}}=$ initial concentration of metal; $\left(\mathrm{mg} . \mathrm{L}^{-1}\right)$;

$\mathrm{C}_{\mathrm{e}}=$ final concentrations of metal, $\left(\mathrm{mg} \cdot \mathrm{L}^{-1}\right)$;

$\mathrm{V}=$ volume of the dye solution $(\mathrm{L})$;

$\mathrm{m}=$ amount of adsorbent $(\mathrm{g})$;

\section{Results and discussion}

\section{FT-IR analysis of clay and modified clay}

FT-IR analysis of clay and modified clay was carried out to see if dodecylamine was successfully incorporated into the clay. Twelve carbon containing dodecyl group, an alkane, gives a stretching peak at $2800-3000 \mathrm{~cm}^{-1}$ corresponding to the $\mathrm{sp}^{3}$ hybridization peaks of alkanes, where raw clay has no such peaks in that region due to absence

Table 1. Different compositions of composite.

\begin{tabular}{|c|c|c|c|}
\hline Composites & Clay (g) & Cellulose (g) & Composition \\
\hline CC1 & 4 & 1 & Clay $80 \%:$ Cellulose $20 \%$ \\
\hline CC2 & 3.5 & 1.5 & Clay $70 \%:$ Cellulose $30 \%$ \\
\hline CC3 & 3 & 2 & Clay $60 \%:$ Cellulose $40 \%$ \\
\hline CC4 & 2.5 & 2.5 & Clay $50 \%:$ Cellulose $50 \%$ \\
\hline CC5 & 2 & 3 & Clay $40 \%:$ Cellulose $60 \%$ \\
\hline CC6 & 1.5 & 3.5 & Clay $30 \%:$ Cellulose $70 \%$ \\
\hline CC7 & 1 & 4 & Clay $20 \%:$ Cellulose $80 \%$ \\
\hline
\end{tabular}

Table 2. Conditions for adsorption test with composite.

\begin{tabular}{|c|c|}
\hline Parameter & Value \\
\hline Temperature & $27^{\circ} \mathrm{C}$ \\
\hline Shaking time & 2 hours \\
\hline $\mathrm{pH}$ & 4 \\
\hline Dose & $50 \mathrm{mg}$ \\
\hline Concentration & $25 \mathrm{ppm}$ \\
\hline Volume & $20 \mathrm{~mL}$ \\
\hline
\end{tabular}

of any hydrocarbons in the structure. So, the presence of peak at 2800 $3000 \mathrm{~cm}^{-1}$ gives a clear indication of successful modification of Bijoypur clay by dodecylamine (Figure 1).

From the FT-IR spectra of raw clay, the peak assigned to water $-\mathrm{OH}$ stretching is found at $3459 \mathrm{~cm}^{-1}$. Further peaks for the stretching of $-\mathrm{OH}$ groups coordinated to the octahedral cations can be found at $3696,3668,3653$ and $3619 \mathrm{~cm}^{-1}$. The bending due to presence of water is observed at $1633 \mathrm{~cm}^{-1}$. The most important mineral peaks are observed at 1114,1030 , and $1006 \mathrm{~cm}^{-1}$ due to Si-O stretching modes. At $912 \mathrm{~cm}$ ${ }^{1}$, the peak is due to presence of bending Al-Al-OH bonds. The strong peaks at $795 \mathrm{~cm}^{-1}$ are because of free silica and/or quartz admixtures, some other peaks can be observed in the finger print region but heavily overlapped are at $754 \mathrm{~cm}^{-1}$ for $\mathrm{Si}-\mathrm{O}-\mathrm{Al}$ bending, $698 \mathrm{~cm}^{-1}$ for $\mathrm{Si}-\mathrm{O}$ stretching, $536 \mathrm{~cm}^{-1}$ for Si-O-Al bending, $468 \mathrm{~cm}^{-1}$ for $\mathrm{Si}-\mathrm{O}-\mathrm{Si}$ in-plane bending, and $428 \mathrm{~cm}^{-1}$ for $\mathrm{Si}-\mathrm{O}$ bonds.

In the FT-IR spectrum of modified clay, all the important peaks are present and they are more or less unchanged as expected. But the presence of alkane peak at $2900 \mathrm{~cm}^{-1}$ clearly shows the incorporation of dodecyl group into the clay. The presence of primary amine from the dodecylamine used for modification gives a narrow band at $3400 \mathrm{~cm}^{-1}$ and also at $1600 \mathrm{~cm}^{-1}$. But these peaks are subdued by the strong peaks from other groups present in raw clay.

\section{FT-IR analysis of composites}

From the FT-IR spectrum, it is clear that peaks from both clay and crystalline cellulose are visible (Figure 2). Major peaks like the alkane peak due to presence of dodecyl group in the modified clay can be found at $2800-3000 \mathrm{~cm}^{-1}$. At $1040 \mathrm{~cm}^{-1}$ due to C-O stretching in alcohols present in crystalline cellulose can be observed in composite. These peaks are particularly dominant in composites CC7, CC6, CC5, CC4, CC 3 and CC2 as peaks from both clay and cellulose have overlapped. Changes in peaks as a result of combination of these can be seen. Whereas, in composite CC1, the peaks of clay and crystalline cellulose are more evident individually, in composite CC7, the peaks are more distorted. This implies a better interaction of clay and crystalline cellulose at higher percentage of cellulose CC7. This may be due to better dispersion and exfoliation of clay as filler material at lower percentage.

\section{Thermogravimetric analysis}

TGA was carried out to get a measure of the thermal stability of the composites. There are two stages of degradation in the thermogram. In the first stage, loss of water could be seen from $40^{\circ} \mathrm{C}$ to $150^{\circ} \mathrm{C}$. After that, in the second stage from $200^{\circ} \mathrm{C}$ to $350^{\circ} \mathrm{C}$, a significant loss in weight was observed (Figure 3). This was due to decomposition of organic component. The temperature of degradation $\left(\mathrm{T}_{\mathrm{deg}}\right)$, referred as the $10 \%$ weight loss, for pure crystalline cellulose containing no clay was $259^{\circ} \mathrm{C}$. But in composite CC7, due to addition of $20 \%$ clay $\mathrm{T}_{\mathrm{deg}}$ increased to $267^{\circ} \mathrm{C}$ which shows increased ability to resist thermal degradation. Moreover, further addition of clay in composites CC6, CC2 and CC1 
showed $\mathrm{T}_{\text {deg }}$ increased to $276^{\circ} \mathrm{C}, 296^{\circ} \mathrm{C}$ and $312^{\circ} \mathrm{C}$ respectively indicating increased resistance to thermal degradation. While modified clay showed no thermal degradation until very high temperature of $480^{\circ} \mathrm{C}$ where organic modifying agents degrades completely. This significant increase in the thermal stability of composites upon addition of clay is a common property of cellulose polymer-clay composites. It appears that the mechanism of thermal degradation in a natural polymer like cellulose is inhibited by the presence of the exfoliated silicate sheets as a result of composite formation.

The final char yields of the materials with various clay compositions are also significantly different. Composites CC7, CC6, CC2 and $\mathrm{CC} 1$ showed increase in char residue. The formation of char in TGA experiments is one measure of thermal stability and flame retardancy. This thermal stability found in clay-cellulose composites arises from the formation of char layers, which is a result of the collapse of exfoliated and/or intercalated structures within the composites. The silicate

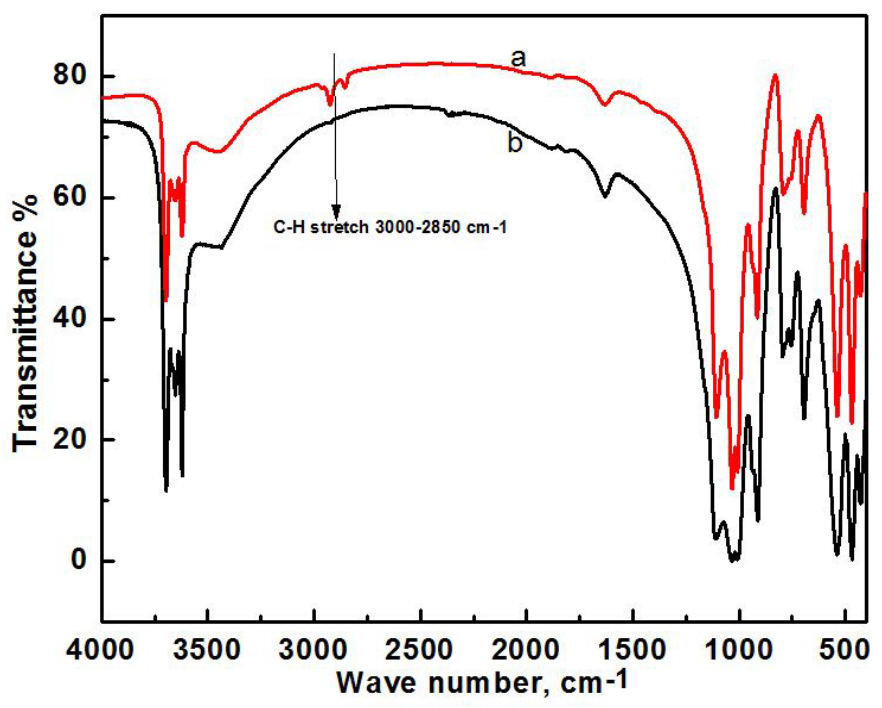

Figure 1. FTIR analysis of raw clay (a), modified clay (b).

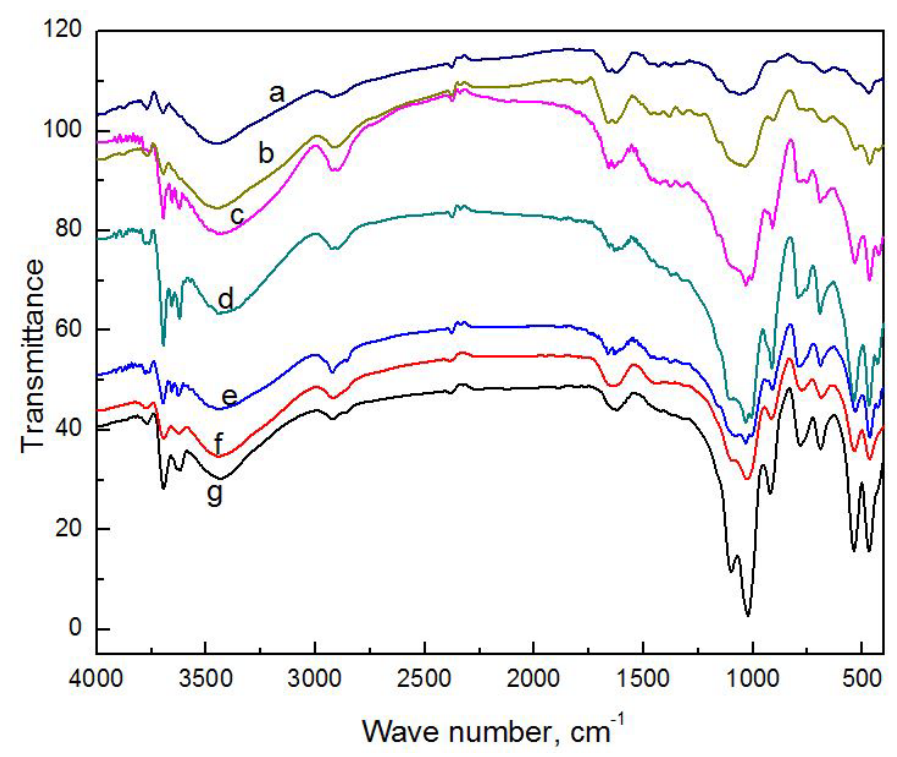

Figure 2. FTIR analysis of different compositions of composite CC7 (a), CC6 (b), CC5 (c), CC4 (d), CC3 (e), CC2 (f), CC1 (g).

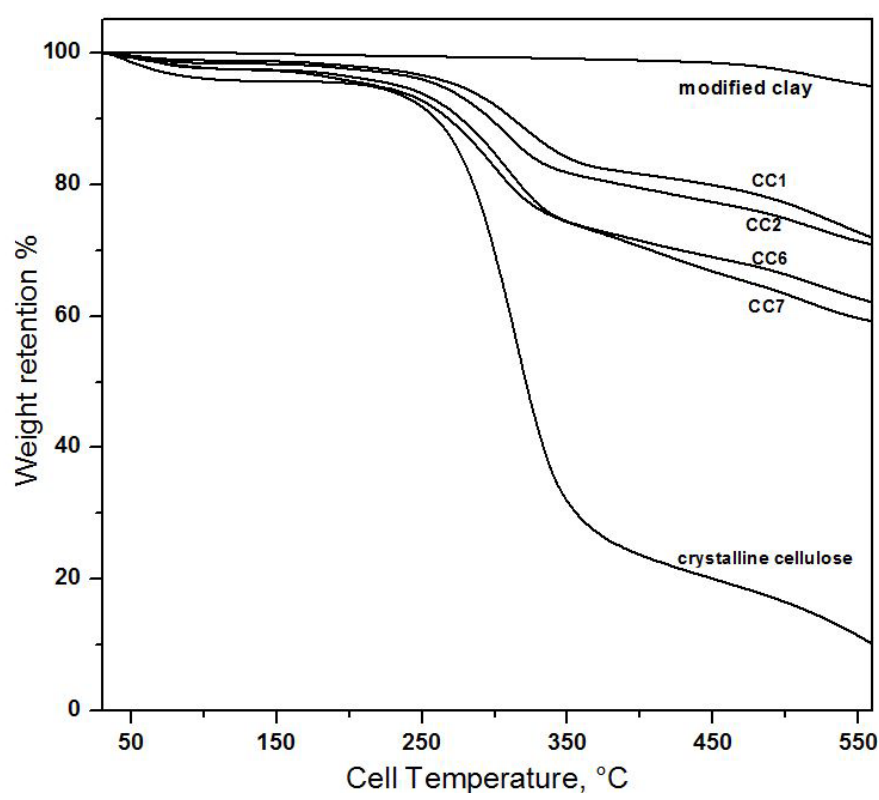

Figure 3. TGA thermogram of modified clay, crystalline cellulose, $\mathrm{CC} 1, \mathrm{CC} 2, \mathrm{CC} 6$ and CC7.

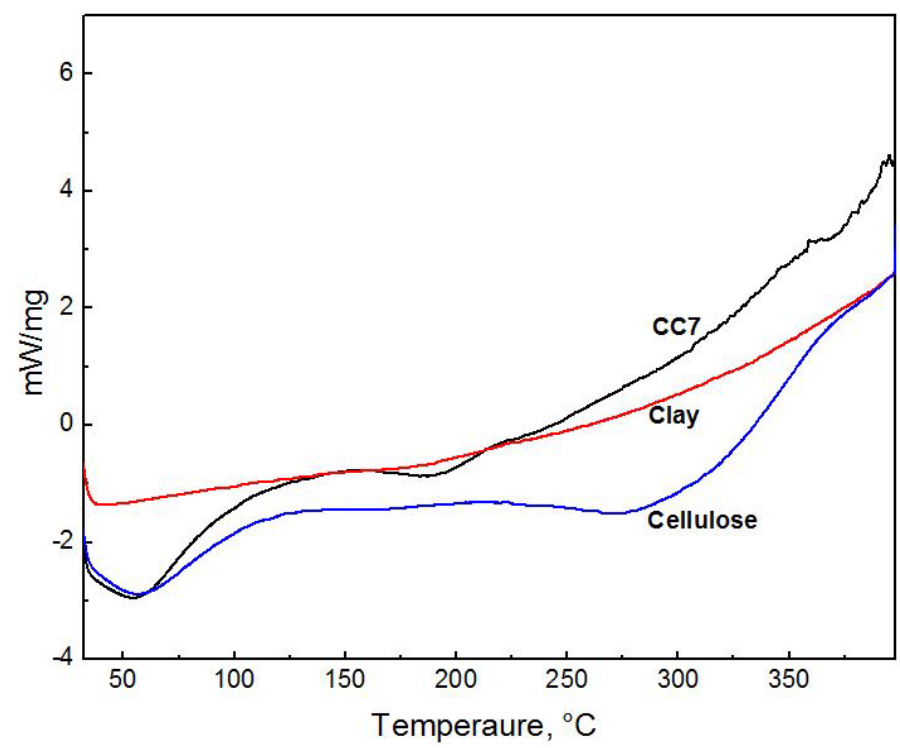

Figure 4. DSC thermogram of composite CC7, modified clay and crystalline cellulose.

structure is believed to act as an insulator and a mass transport barrier, slowing the escape of volatile decomposition products. As a result, char yield increases as percentage of clay was increased in the composite.

\section{Differential scanning calorimetry analysis}

From the DSC thermogram, the modified clay exhibits no change in chemical or physical state within the temperature range of $30^{\circ} \mathrm{C}$ to $400^{\circ} \mathrm{C}$ (Figure 4). While crystalline cellulose shows endothermic peak around $100^{\circ} \mathrm{C}$. Cellulose decomposes at a temperature excess of $347^{\circ} \mathrm{C}$. In case of composite, the exothermic temperature peak can be seen from $75^{\circ} \mathrm{C}$ to $100^{\circ} \mathrm{C}$. The presence of clay in composite has changed the decomposition rate. It shows better thermal stability than natural crystalline cellulose which is apparent from the DSC curve. Above $225^{\circ} \mathrm{C}$, while cellulose shows degradation, composite shows no change in thermogram despite temperature rise. 


\section{Scanning electron microscopy analysis}

Scanning electron microscopy (SEM) images of different composition of composites show significant difference in morphology of composites. The stark contrast between crystalline cellulose, modified clay, composite $\mathrm{CC} 1$ and $\mathrm{CC} 7$ are clearly visible from their SEM images at $1000 \times$ magnification. (Figure 5A, 5B, 5C, 5D).

From the SEM images, it is evident that there is no separate cellulosic fiber visible in composite. Moreover, clay particles are not distinct either. In composite $\mathrm{CC} 1$, the structure of the composite surface is compact. The surface is rough and porous. It is impossible to distinguish either cellulose or clay even at $1000 \times$ magnification. Cellulose fiber has changed its structure. Instead of fibrous structure, it looks more like slates here.

In composite CC7, with $80 \%$ crystalline cellulose, the structure is more filled and less porous. It is difficult to separate individual particles. The structure looks layered with smoother surface.

\section{Comparative adsorption study}

The adsorption capacity was calculated using the previously mentioned equation (1). After the adsorption process was carried out, the results from AAS analyzer are shown below (Table 3).

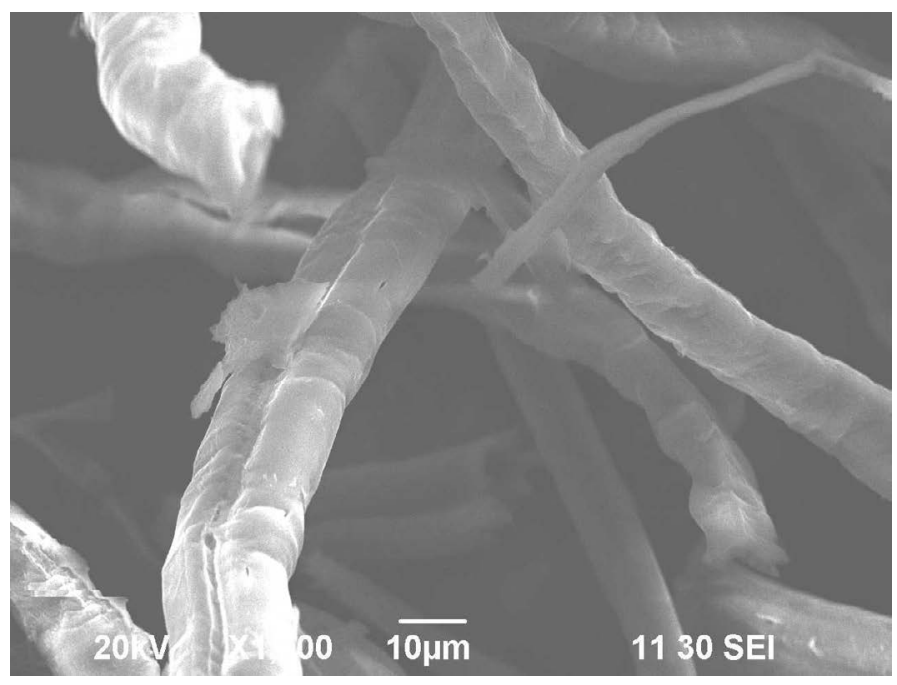

Figure 5A. SEM image of crystalline cellulose at $1000 \times$ magnification.

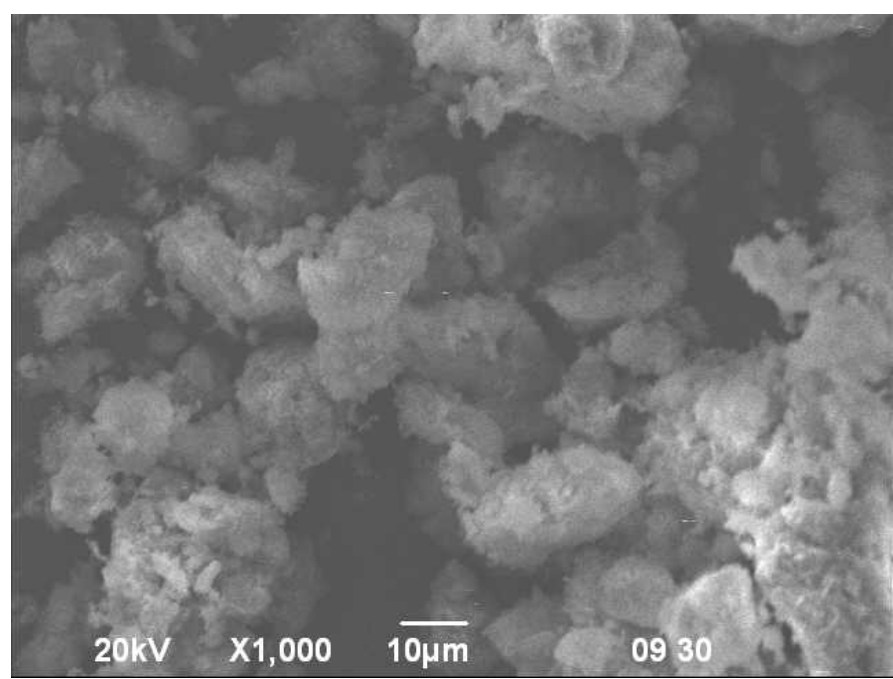

Figure 5B. SEM image of modified clay at $1000 \times$ magnification.

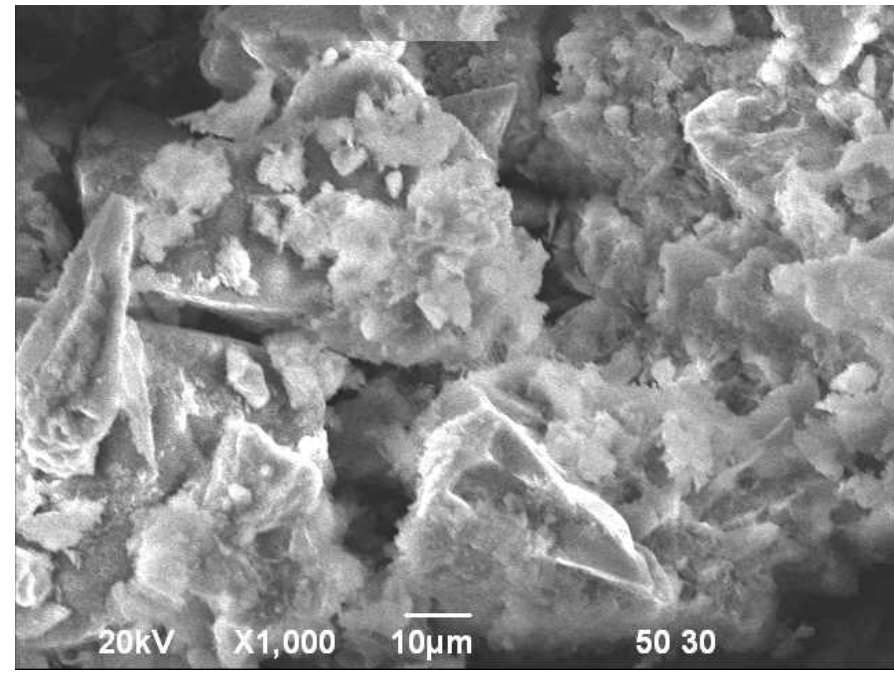

Figure 5C. SEM image of composite $\mathrm{CC} 1$ at $1000 \times$ magnification.

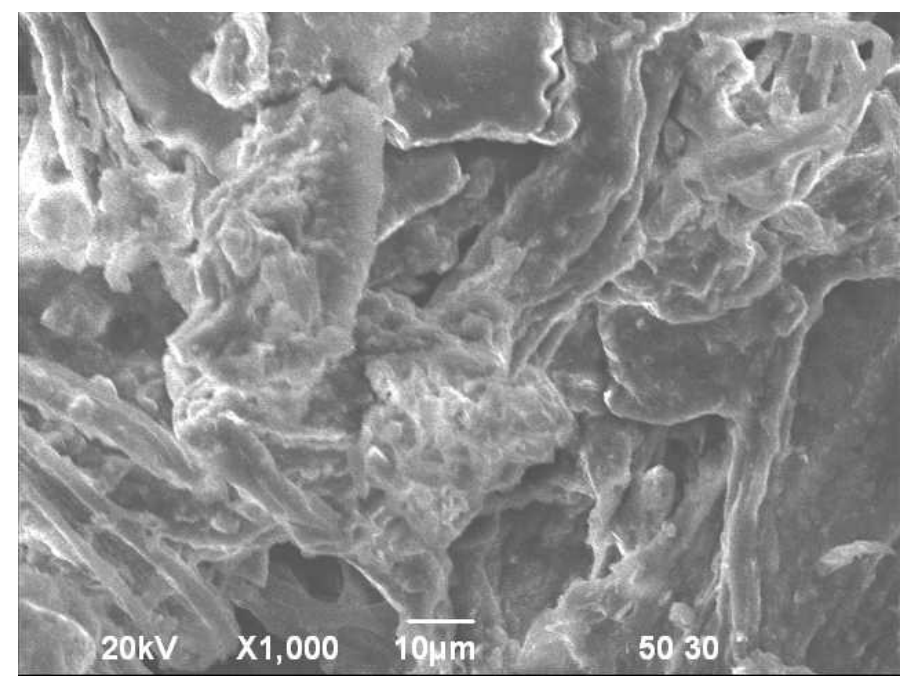

Figure 5D. SEM image of composite CC7 at $1000 \times$ magnification.

Table 3. Adsorption capacity of composites.

\begin{tabular}{|c|c|}
\hline Adsorbent & Capacity(mg/g) \\
\hline Crystalline Cellulose & 0.39 \\
\hline CC 7 & 2.37 \\
\hline CC 6 & 2.34 \\
\hline CC 5 & 2.27 \\
\hline CC 4 & 2.17 \\
\hline CC 3 & 2.06 \\
\hline CC 2 & 2.04 \\
\hline CC 1 & 1.97 \\
\hline Clay & 0.67 \\
\hline Modified Clay & 1.80 \\
\hline
\end{tabular}

The best adsorption capacity was observed in case of CC7 (2.37 $\mathrm{mg} / \mathrm{g})$. It was better than raw clay $(0.67 \mathrm{mg} / \mathrm{g})$ or crystalline cellulose $(0.39 \mathrm{mg} / \mathrm{g})$. The capacity has increased almost five to six times. The lowest capacity improvement was in $\mathrm{CC} 1$, where percentage of clay was significantly higher than cellulose. Raw clay showed higher adsorption capacity than crystalline cellulose. In case of cellulose, the only adsorption site is the - $\mathrm{OH}$ groups present on the hydrocarbon structure. Hexavalent chromium is found as bichromate ion $\left(\mathrm{HCrO}_{4}^{-}\right)$and dichromate $\left(\mathrm{Cr}_{2} \mathrm{O}_{7}^{2-}\right)$ in acidic medium. But in weak acidic medium, the bichromate anion is the major species. The interaction between 
cellulose and bichromate ions is possible because of the hydroxyl protons in cellulose and the oxygen atoms in the bichromate anions forming hydrogen bond.

On the other hand, two different sites for chromium adsorption are available in clay. One of them is the broken bond surfaces at the edge, while the other is the basal faces. This basal face have charges which originates from isomorphous substitution within both tetrahedral and octahedral sheets. The adsorption is due to mainly cation exchange and surface complexation. In this case, the surface at the amphoteric edges sites is the most relevant. This is because, at lower $\mathrm{pH}$ the hydroxyl group on the clay surface is converted to $\mathrm{Si}-\mathrm{OH}^{2+}$, resulting interaction between bichromate ion $\left(\mathrm{HCrO}_{4}^{-}\right)$and clay surface. Moreover, modified clay showed higher adsorption capacity than raw clay due to presence of $-\mathrm{NH}_{2}$ group in the structure as a result of modification with dodecyl amine. In acidic medium, this amine $-\mathrm{NH}_{2}$ is converted into $\mathrm{NH}_{3}^{+}$. So there is a new site for interaction between $\mathrm{NH}_{3}^{+}$with bichromate ion $\left(\mathrm{HCrO}_{4}^{-}\right)$and also dichromate ion $\left(\mathrm{Cr}_{2} \mathrm{O}_{7}^{2-}\right)$ due to electrostatic action.

There is a gradual increase in adsorption capacity with the increase in cellulose content in composites. This can be attributed to better interaction of clay and crystalline cellulose in composites where cellulose percentage is high. In CC7, the composite is expected to have better dispersion and exfoliation of filler material, clay, than in CC1 where cellulose percentage is lower. Better exfoliation increases the gallery space in layered silicates, thus opening new avenue for chromium adsorption. As the cellulose percentage was decreased, the adsorption capacity dropped gradually. Lower percentage of cellulose results in poor exfoliation of clay layers. As a consequence, possibility of chromium adsorption between clay layers lessens as the gallery space is not increased.

\section{Conclusion}

From the above study, it is clear that Bijoypur clay and jute fiber can be successfully incorporated to fabricate a polymer-layered silicate biocomposite. FTIR and SEM study showed good incorporation and significant changes in their structure. Moreover, even at different weight variation of starting components, composite material was able to show enhanced properties, though better results were obtained in composites where percentage of cellulose was higher than clay. Not only this, this green and environment friendly composite can be applied to function as adsorbent for the removal of hazardous heavy metal such as chromium. A comparative study against natural adsorbent like surfactant modified clay and cellulose showed better adsorption capacity of the composite. Furthermore, an improved thermal property indicates the capacity of the composite to withstand high temperature without losing structural integrity. Thus, a biocomposite with improved adsorption capacity could be prepared from locally available raw materials.

\section{References}

1. Park JH, Jana SC (2003) Mechanism of exfoliation of nanoclay particles in epoxy-clay nanocomposites. Macromolecules 36: 2758-2768.

2. Chen CaDC (2003) Processing and Morphological Development of Montmorillonite Epoxy Nanocomposites. Nanotechnol 14: 643-648.

3. Messersmith PBaEPG (1994) Synthesis and characterization of layered silicate-epoxy nanocomposites. Chem Mater 6: 1719-1725.

4. Okamoto M, Morita S, Kim Y, Kotaka T, Tateyama H (2001) Dispersed structure change of smectic clay/poly (methyl methacrylate) nanocomposites by copolymerization with polar comonomers. Polym 42: 1201-1206.

5. Choi HJ, Kim SG, Hyun YH, Jhon MS (2001) Preparation and rheological characteristics of solvent-cast poly (ethylene oxide)/montmorillonite nanocomposites. Macromol Rapid Commun 22: 320-325.
6. Cheng D1, Xia H, Chan HS (2005) Synthesis and characterization of surfacefunctionalized conducting polyaniline-chitosan nanocomposite. J Nanosci Nanotechnol 5: 466-473. [Crossref]

7. Lu H, Hu Y, Yang L, Wang Z, Chen Z, et al. (2005) Preparation and thermal characteristics of silane-grafted polyethylene/montmorillonite nanocomposites. $J$ Mater Sci 40: 43-46.

8. Wang X, Du Y, Luo J, Lin B, Kennedy JF (2007) Chitosan/organic rectorite nanocomposite films: Structure, characteristic and drug delivery behaviour. Carbohydr Polym 69: 41-49.

9. Ray SS, Bousmina M (2005) Biodegradable polymers and their layered silicate nanocomposites: in greening the 21st century materials world. Progress in Materials Science 50: 962-1079.

10. Park H-M, Liang X, Mohanty AK, Misra M, Drzal LT (2004) Effect of Compatibilizer on Nanostructure of the Biodegradable Cellulose Acetate/Organoclay Nanocomposites. Macromolecules 37: 9076-9082.

11. Park H-M, Mohanty AK, Drzal LT, Lee E, Mielewski DF, et al. (2006) Effect of Sequential Mixing and Compounding Conditions on Cellulose Acetate/Layered Silicate Nanocomposites. Journal of Polymers and the Environment 14: 27-35.

12. Zhuang $\mathrm{H}$, Zheng JP, Gao H, De Yao $\mathrm{K}$ (2007) In vitro biodegradation and biocompatibility of gelatin/montmorillonite-chitosan intercalated nanocomposite. $J$ Mater Sci Mater Med 18: 951-957.

13. Ray SS, Yamada K, Okamoto M, Ueda K (2003) Control of biodegradability of polylactide via nanocomposite technology. Macromol Mater Eng 288: 203-208.

14. Li P, Ping Zheng J, Lu Ma Y, De Yao K (2003) Gelatin/montmorillonite hybrid nanocomposite. II. Swelling behavior. J Appl Polym Sci 88: 322-326.

15. Maiti PB, CA Giannelis , E.P. (2003) Renewable plastics: synthesis and properties of PHB nanocomposites. Polym Mater Sci Eng 88: 58-59.

16. Ioelovich M (2008) Cellulose as a nanostructured polymer: a short review. BioResources 3: 1403-18.

17. McCormick C (2010) Nanocellulose steps up on stage. Pulp Paper-Canada 111: 15-16.

18. Azizi Samir MAS, Alloin F, Dufresne A (2005) Review of recent research into cellulosic whiskers, their properties and their application in nanocomposite field. Biomacromolecules 6: 612-626.

19. Ngah WW, Hanafiah MAKM (2008) Removal of heavy metal ions from wastewater by chemically modified plant wastes as adsorbents: a review. Bioresour Technol 99: 3935-3948.

20. Thirumavalavan M, Lai Y-L, Lin L-C, Lee J-F (2009) Cellulose-based native and surface modified fruit peels for the adsorption of heavy metal ions from aqueous solution: Langmuir adsorption isotherms. J Chem Eng Data 55: 1186-1192.

21. Mututuvari TM, Tran CD (2014) Synergistic adsorption of heavy metal ions and organic pollutants by supramolecular polysaccharide composite materials from cellulose, chitosan and crown ether. J Hazard Mater 264: 449-459. [Crossref]

22. Kim K, Utracki LA, Kamal MR (2004) Numerical simulation of polymer nanocomposites using self-consistent mean-field model. J Chem Phys 121: 1076610777. [Crossref]

23. Pinnavaia TJ (1983) Intercalated clay catalysts. Science 220: 365-371. [Crossref]

24. Cadena F, Rizvi R, Peters RW (1990) Feasibility studies for the removal of heavy metals from solution using tailored bentonite. In: Feasibility studies for the removal of heavy metals from solution using tailored bentonite, pp: 77-94.

25. Uddin F (2008) Clays, nanoclays, and montmorillonite minerals. Metallurgical and Materials Transactions A 39: 2804-2814.

26. López-Galindo A, Viseras C, Cerezo P (2007) Compositional, technical and safety specifications of clays to be used as pharmaceutical and cosmetic products. Appl Clay Sci 36: 51-63.

27. Mousharraf A, Hossain MS, Islam MF (2012) Potential of locally available clay as raw material for traditional-ceramic manufacturing industries. J Chem Eng 26: 34-37.

28. Hassmanova V, Vanecková J, Bousova K (1999) Occupational diseases caused by chromium and its compounds. Acta Medica (Hradec Kralove) Suppl 43: 33-36.

29. Kanerva L, Jolanki R, Estlander T, Alanko K, Savela A (2000) Incidence rates of occupational allergic contact dermatitis caused by metals. Am J Contact Dermat 11 155-160. [Crossref]

30. Tenório JA1, Espinosa DC (2001) Treatment of chromium plating process effluents with ion exchange resins. Waste Manag 21: 637-642. [Crossref] 
Islam MM (2017) Preparation and characterization of bijoypur clay-crystalline cellulose composite for application as an adsorbent

31. Nicell JA, Saadi KW, Buchanan ID (1995) Phenol polymerization and precipitation by horseradish peroxidase enzyme and an additive. Bioresour Technol 54, 5-16.

32. Aliane A, Bounatiro N, Cherif AT, Akretche DE (2001) Removal of chromium from aqueous solution by complexation-ultrafiltration using a water-soluble macroligand. Water Res 35: 2320-2326. [Crossref]
33. Leinonen H, Lehto J. (2001) Purification of metal finishing waste waters with zeolites and activated carbons. Waste Manag Res 19, 45-57.

34. Nakagaito AN, Yano H (2008) The effect of fiber content on the mechanical and thermal expansion properties of biocomposites based on microfibrillated cellulose. Cellulose 15: 555-559.

Copyright: (C2017 Islam MM. This is an open-access article distributed under the terms of the Creative Commons Attribution License, which permits unrestricted use, distribution, and reproduction in any medium, provided the original author and source are credited. 